\title{
Neighborhood Effects on Racial-Ethnic Identity: The Undermining Role of Segregation
}

\author{
Daphna Oyserman · Kwang-Il Yoon
}

Received: 30 December 2008/Accepted: 5 April 2009/Published online: 22 April 2009

(C) Springer Science+Business Media, LLC 2009

\begin{abstract}
African American and Latino youth experience stereotypes about their group's academic ability but youth high in three components of racial-ethnic identity Connectedness, Awareness of Racism, and Embedded Achievement are buffered from these stereotypes and are more likely to attain good grades in school, feel efficacious, and engaged with academics. In the current study, the effect of neighborhood segregation on these components of racial-ethnic identity was examined. Segregation impairs racial-ethnic identity Connectedness, Awareness of Racism, and Embedded Achievement among African American and Latino youth. Eighth graders $(n=206$ African American, $n=131$ Latino) living in 100 census tracks filled out racial-ethnic identity scales. A multilevel model demonstrates that segregation is associated with lower scores on each of the components of racial-ethnic identity.
\end{abstract}

Low-income African Americans are likely to live in raciallyethnically segregated neighborhoods (Massey and Eggers 1990) and racial-ethnic segregation has negative effects on academic outcomes (Bankston and Caladas 1996; Hanushek et al. 2002; Peterson and Krivo 1993; Wacquant and Wilson 1989). Whereas racial-ethnic segregation was not historically income-based, shifts in the labor market have produced a concentration of low income racial-ethnic minorities in urban centers. The American labor market is now "post industrial"

D. Oyserman $(\bowtie)$

Institute for Social Research, University of Michigan, 426

Thompson Avenue, Ann Arbor, MI 48106-1248, USA

e-mail: daphna.oyserman@umich.edu

K.-I. Yoon

Rackham Graduate School, University of Michigan, 426

Thompson Avenue, Ann Arbor, MI 48106-1248, USA

e-mail: kiyoon@umich.edu which means that there are now fewer jobs for low skill workers and especially fewer good wage manufacturing jobs for these workers, with an increase in the proportion of the labor market working in service jobs (Eggers and Massey 1992; Wilson 1996). In addition to this contraction in the size of the labor market and shift in focus from manufacturing to service, wages have become more polarized, with better paying jobs shifting away from central cities. As the market shifted, those with job skills or the resources to attain these skills followed high skill jobs out of central cities, leaving behind those who lacked skills and did not have the resources to attain them. This resulted in increasingly segregated and high poverty urban centers with fewer and worse paying jobs (Eggers and Massey 1992; Wilson 1996). This spatial segmentation and separation means that residents of segregated neighborhoods have little exposure to people who have high education, income, or occupational prestige (Adelman and Gocker 2007; Krivo et al. 1998; Massey et al. 1994). Because African American and Latino children are disproportionately likely to live in these segregated neighborhoods (Wallace and Muroff 2002), in the current article we examine the impact of neighborhood segregation on the racial-ethnic identities of African American and Latino youths, controlling for poverty and unemployment.

We use the term racial-ethnic identity purposely. Race and ethnicity are likely to form a multifaceted identity that includes sense of membership, valued goals, norms, and behaviors perceived to be shared by in-group members and beliefs about how the in-group is perceived by others (Oyserman et al. 2007). ${ }^{1}$ In the current article, we first lay out the theoretical argument, starting with prior research demonstrating that racial-ethnic identity can have positive

\footnotetext{
${ }^{1}$ We refer to identity with regard to these content domains rather than simple categorization of individuals into a group.
} 
consequences for academic attainment when youth are simultaneously high in each of the three core racial-ethnic identity components (embedded achievement, awareness of racism, and connectedness). We outline why segregation is likely to undermine racial-ethnic identity. Finally, we provide supporting evidence, using new data to examine the impact of segregation, neighborhood poverty, and unemployment on each of these components of racialethnic identity. We hypothesize that racial-ethnic segregation has a unique corrosive effect on racial-ethnic identity, controlling for poverty, and unemployment. While much of the literature has focused explicitly on African Americans, we include both Latino and African Americans in our analyses.

\section{Racial-Ethnic Identity: A Basic Operationalization}

Self-concept is a theory about oneself, what one thinks about when one thinks about oneself. Self-concept is experienced as both content (who one was, is, and may become, and how one fits in) and as process (what one's goals are, what one is trying to do) (Oyserman and Markus 1993). In that sense, motivation is identity-based (for a review, Oyserman et al. 2007). A basic theoretical underpinning of many models of racial-ethnic identity is social identity theory (Tajfel and Turner 1986). From a social identity theory perspective, positive in-group identity (operationalized as a positive sense of belonging and connection to important social groups) produces both feelings of self-worth and motivation to enact group identity (see also Luhtanen and Crocker 1992). Racial-ethnic identities are likely to be part of selfconcept (Howard 2000; Oyserman 2008) for a number of reasons. First, membership in racial and ethnic groups matter for how individuals make sense of themselves and others. Second, membership in racial and ethnic groups is associated with beliefs about commonalities in experience (including shared history, language, and traditions). Third, membership in racial and ethnic groups is associated with beliefs about possible future outcomes.

As a part of self-concept, racial-ethnic identities are implicated in each of the three basic self-processes-protecting or feeling good about oneself, knowing oneself, and improving oneself (Oyserman et al. 1995; Oyserman and Markus 1993). In its self-protective function, racial-ethnic identities buffer youth from vulnerability to stereotypes. In its self-knowledge function, racial-ethnic identities facilitate feelings of self-worth while providing an organizing frame or lens with which to make sense of the social world and other's responses to the self. In its self-improvement function, racial-ethnic identities motivate persistent goalpursuit, particularly engagement with school and academic attainment.

\section{Effects of Segregation on Racial-Ethnic Identity}

Even though racial-ethnic segregation has not been central to recent racial-ethnic identity research, it was clearly central to early research perspectives. Arguably the most central of these were the doll studies conducted by Clark and Clark (1939). They demonstrated that boys and girls aged 4-7 who identified white dolls as good and black dolls as bad were more likely to choose the white dolls rather than the black ones as similar to themselves.

Clark and Clark (1939) interpreted their findings as a demonstrating the identity-undermining effects of racial segregation on young African American boys and girls. Their results and interpretation were cited in the Supreme Court's landmark 1954 ruling in Brown v. Board of Education. In his further writings, Clark (1965/1989) argued that segregation has negative effects on identity no matter whether individuals experiencing segregation do or do not explicitly see segregation as problematic. The socially prescribed and legally supported segregation Clark (1965/1989) referred to differs in some important regards to the de facto segregation found in America today (see Massey and Denton 1989, 1993). However, Clark's (1965/1989) idea that segregation in high poverty and low employment contexts provides youth with daily experience of doubt about the collective efficacy of their group still warrants examination.

\section{Racial-Ethnic Identities, Well-Being, and Self-Esteem}

Perhaps in response to the Clark's (Clark and Clark 1939) work, post civil rights literature on racial-ethnic identities focused on demonstrating that doll choice had changed (e.g., Hraba and Grant 1970) and that racial-ethnic identity was positively associated with indicators of mental health and self-esteem. Focusing on African Americans and using a variety of measures and samples, these studies consistently documented a positive association between low wellbeing and low racial identification among high school and college students and non-college adults. For example, low racial-ethnic identity (operationalized as acceptance of stereotypes about in-group achievement) was associated with depressive symptoms among African American but not European American 17-year-olds (Arroyo and Zigler 1995). Low racial-ethnic identity (operationalized as lack of connectedness to in-group and lack of awareness of racism) was associated with low well-being and low selfesteem in women college students and non-college adult women (Pyant and Yanico 1991). These results were substantively replicated in later studies involving Ethiopian immigrants to the US (Kibour 2001), African American men (Pierre and Mahalik 2005) and African American university students (Pillay 2005). In each case, negative 
feelings toward racial-ethnic in-group consistently related to poorer well-being.

Other research has demonstrated a positive association between positive feelings about and connection to one's racial-ethnic in-group and self-esteem (e.g., Parham and Helms 1985; Rowley et al. 1998; Sellers et al. 1998; Vandiver et al. 2002; Worrel et al. 2004; for a review see Swanson et al. 2003). Similar results were found when Hispanics were included in the analyses. For example, in a large scale survey of Colorado public school students, Latino and African American youth did not differ in level of racial-ethnic identity and higher racial-ethnic identity scores were positively related to self-esteem, self-confidence, and felt purpose in life across racial-ethnic groups (Martinez and Dukes 1997).

\section{Racial-Ethnic Identity and Academic Outcomes}

Having established that low racial-ethnic identity is associated with worse well-being, research turned to understanding when racial-ethnic identity can promote academic attainment. Here focus has been on the negative consequences of stereotypes, especially stereotypes about the academic engagement and ability of African Americans (Steele 1997). Rather than attempt to assess racial-ethnic identity directly, this work focuses on the negative consequences of racial-ethnic stereotypes of inability on academic performance. In this way, it connects back to the Clark's early interest in stereotypes and identity. While the early doll studies attempted to assess identity indirectly via doll choice, these studies use experimental methods to assess the consequences of cued stereotypes on academic performance.

Across studies, performance on a stereotype-relevant task (e.g., math) declines when racial-ethnic group membership is cued if the stereotype about group ability on the task is negative (see Steele et al. 2002 for a review). Simply being reminded of one's membership in a stereotyped group prior to task engagement is consequential for later performance. Results were found for African American college students in Steele's initial studies (Steele 1997), and later replicated with other social identities, including social class and gender (see Steele et al. 2002 for a review). Taken together, these results support the Clark's (1939, 1965/1989) early assertion that negative stereotypes matter but do not explicitly examine the originally posited relationship between racial-ethnic identity, academic attainment, and segregation per se. This is the focus of our current study.

The idea that positive racial-ethnic identity should be associated with positive school outcomes can be seen as the flip side of the Clark's (1965/1989) assumption that segregation undermines positive racial identity and in this way undermines performance. Though quite a few authors have predicted a positive relationship between racial-ethnic identity and academic outcomes, demonstrating that such a relationship exists has proven difficult (Chavous et al. 2003; Chavous et al. 2002; O'Brien et al. 1999; Sellers et al. 1998). In developing their tripartite model of racial-ethnic identity, Oyserman et al. argued that the problem is that the two commonly postulated components of racial-ethnic identity-positive feelings of connection to in-group and awareness of racism, are associated with selfesteem but not with school performance and grades (Oyserman et al. 1995). They suggested that what is missing from other formulations of content of racial-ethnic identity is content focusing attention on academic performance as a valued goal of racial-ethnic in-group members (Oyserman et al. 1995).

In the above context, while positive sense of in-group connection and awareness of racism are sufficient for the self-protection and self-knowledge functions of racialethnic identity, they are insufficient for the self-improvement function of racial-ethnic identity-the attainment of school success in a sometimes hostile environment. What is missing is the belief that school success is an in-group goal and that activities and strategies to attain success can effectively be used by in-group members (Oyserman et al. 2007; Oyserman et al. 2006; Oyserman 2008). In conjunction with positive feelings of in-group connection and awareness of racism, the belief that achievement is embedded in in-group membership should focus attention on in-group values, clarify that school performance is an in-group value, and buffer youth from negative consequences of failures (which may be due to racism).

Oyserman et al. did not postulate and did not find a main effect of any single racial-ethnic identity component (Oyserman et al. 1995). They argued that embedded achievement alone is insufficient because it does not protect students from negative stereotypes the way awareness of racism does. Similarly, they argued that awareness of racism alone is insufficient because it does not focus youth's energies on academic attainment.

Rather than a main effects or summative model, Oyserman's tripartite model posited a three-way interaction for a number of reasons. First, racial-ethnic identity is multivariate; not only must individuals self-define across multiple dimensions, but also the particular pattern of responses matters. Racial-ethnic identity is predicted to have positive effects on school performance and grades only when youth score high in each of three the basic components of racial-ethnic identity, which they termed Connectedness, Awareness of Racism, and Embedded Achievement (Oyserman et al. 2007; Oyserman et al. 1995). 
Youth scoring highly only on a single component were not expected to be able to successfully focus persistent motivation and effort on attaining school success. Success was not predicted unless the motivational resources from the combination of connectedness, awareness of racism, and embedded achievement were available. Note that the interaction model cannot be tested using a sum score across components. A simple sum, adding up endorsement across each component of racial identity, would not allow for analyses of how each component influenced outcomes in the context of the other ones. That is because sum scores are ambiguous except in the two specific cases in which a sum and a three-way interaction are the same (low scores on all three components and high score on all three components). In all other cases, sum scores would be ambiguous as to content (for example, is a middling score due to high score on connectedness and low score on embedded achievement and awareness of racism or due to mid range scores on all three, and so on). Ambiguous scoring cannot be used to support or disconfirm the specific theorizing of the tripartite model.

The tripartite model was tested in a number of studies (Oyserman et al. 2007, 1995). Taken together, these studies support the hypothesized interaction effect-no single component of racial-ethnic identity alone had a positive consequence for school success. Rather, positive interaction effects were found-when youth scored high on multiple components of racial-ethnic identity academic outcomes improved (for reviews, Oyserman et al. 2007; Oyserman 2008). To clarify the causal process, the initial study manipulated identity salience by asking students to describe their racial-ethnic identity either before they worked on math problems or afterwards (Oyserman et al. 1995). The hypothesis was that thinking about racial-ethnic identity could undermine math success for students if what came to mind did not remind students that school success is an in-group goal (embedded achievement) while also reminding students that the in-group is a valued part of identity (connectedness) and that stereotypes exist (awareness of racism). Student performance would suffer unless all three components of racial-ethnic identity came to mind. As predicted, the four-way interaction was significant-racial-ethnic identity protected performance when racial-ethnic identity was brought to mind and contained all three identity components.

This first study demonstrated that racial-ethnic identity could have a positive effect on academic performance. Follow-up studies asked if racial-ethnic identity really did predict academic performance in the world outside a controlled experiment. Effects of racial-ethnic identity over time were found for grades (school-reported grade point average over 2 years, Altschul et al. 2006), teacher-reported in-class behavior (Oyserman 2008), and youth-reported school efficacy and concern (Oyserman et al. 2003a; Oyserman et al. 2001).

\section{Back to the Beginning: Consequences of Segregation on Racial-Ethnic Identity}

While important as a demonstration that racial-ethnic identity can have positive effects on academic performance in African American and Latino youth from low-income schools, studies using Oyserman's tripartite model have not explicitly addressed the questions raised by Clark's assertion that segregation itself is pernicious because it undermines positive racial-ethnic identity. A number of authors have speculated about the process by which segregation's negative effects might occur (House 2002, Sampson 2003; Taylor et al. 1997). One possibility is that segregated neighborhoods increase social isolation, affording fewer opportunities for positive support, participation and engagement and reducing sense of mutual trust, shared expectations, and collective efficacy (House 2002, Sampson 2003; Taylor et al. 1997). We expect that these negative effects are likely to be enhanced when race-ethnicity, economic disadvantage, and low education are conflated such that youth see that people like them are generally disadvantaged. Because poverty is stigmatizing, growing up in low-income, racially concentrated neighborhood reduces opportunities to see one's group in a positive light, undermining positive identity development (Phillips and Pittman 2003).

Some support our prediction that racial-ethnic identity is impaired by the combined effect of living in low income and racially-ethnically concentrated neighborhoods comes from qualitative analyses of African American boys (Stevenson 1995, 2005). In addition, Bennett (2006) provides supporting correlational evidence. Bennett (2006) asked low income African American teens from Cleveland Ohio, whether they experienced a number of markers of neighborhood blight such as drug addicts asking them for money and worrying that others might try to take their clothes, shoes, or money. He also asked questions about racialethnic identity, assessed as connection to in-group (feeling pride in group membership, a strong sense of belonging to in-group). In this sample, higher neighborhood blight scores were associated with lower racial-ethnic identity scores. Thus, while intriguing, evidence to date is thinstudies do not demonstrate that the components of racialethnic identity relevant to academic performance are undermined by segregation over and above effects of poverty and unemployment.

\section{Hypotheses}

Literature to date suggests that even in low-income and segregated neighborhoods racial-ethnic identity matters and that neighborhoods may matter. Following this 
literature, we hypothesize that racial-ethnic segregation will undermine the components of racial-ethnic identity relevant to academic attainment. Youth living in raciallyethnically concentrated low income neighborhoods will score lower on connectedness, awareness of racism, and embedded achievement.

\section{Method}

\section{Sample}

Eighth graders $(n=353$, girls $n=188$, boys $n=165$, African Americans $n=212$, Latinos $n=141$ ) attending five Detroit middle schools participated as part of a larger study. Data from 63 students who described themselves as non-recent immigrant white or as more recent immigrants from the Middle East (e.g., Yemenite, Chaldean) and Eastern Europe (e.g., Bosnia, Serbia) were excluded. Analyses focus on the $n=337$ youth for whom link to census track data was possible (African Americans $n=206$, Latinos $n=131$ ).

\section{Procedure}

Students filled out the brief questionnaire in their homeroom in the first few weeks of the school year. A letter explaining the study was mailed to parents or guardians of potential participants in English and Spanish explaining the study with follow-up phone calls to answer any questions, newly enrolled students or students for whom a correct address was not available were given a letter, and consent form to take home. Address was used to link questionnaire to Census data and then destroyed.

\section{Measures}

\section{Racial-Ethnic Identity}

Racial-ethnic identity was assessed using the four-item Connectedness, Awareness of Racism, and Embedded Achievement racial-ethnic identity scales previously used in studies of the tripartite model (e.g., Oyserman et al. 2001). The items were derived from content analyses of openended responses and have proven to be predictive of academic outcomes as hypothesized (e.g., Oyserman et al. 2001). Response options were anchored at $1=$ strongly disagree and $5=$ strongly agree (five-point Likert's response options). To tailor questions, participants were asked to first fill in their racial-ethnic identity group and then respond to the questions with regard to their own racialethnic identity group. Students could use any word or phrase to describe their own racial-ethnic identity group as they saw fit. African American students mostly wrote in Black, Latino students mostly wrote in Mexican or Latino or Hispanic. Reliability for each brief scale was adequate and variability was about the same whether calculated as a total across the sample or as nested within census tract. In addition to the mean, standard deviation and pooled standard deviation (presented in parentheses for comparison purposes), an example item for each scale is presented filling in the word "Black" in each blank for ease of reading. Connectedness $M=4.07, S D=0.72$ (pooled $S D=0.75$ ), $\alpha=.73$, sample item "I feel part of the Black community." Embedded Achievement $M=3.72, S D=0.77$ (pooled $S D=0.81), \alpha=.67$, sample item "It is important for my family and the Black community that I succeed in school." Awareness of Racism $M=3.18, S D=0.90$ (pooled $S D=0.86), \alpha=.69$, sample item "Because I am Black, others may have negative expectations of me."

\section{Neighborhood Context Variables}

We examined four variables, education (operationalized as percentage of adults with less than a high school education), poverty (operationalized as percentage of households living below the poverty line), unemployment (operationalized as the percentage of individuals aged 16 and over in the labor force and unemployed), and segregation (operationalized with the Neighborhood Diversity Index).

Initial analyses demonstrated that some of our neighborhood context variables were highly correlated, while others were not. Thus, poverty and unemployment were highly correlated $(r=.53, p<.001)$, and education and poverty were also correlated $(r=0.31, p<.01)$ but education was not correlated with unemployment $(r=-.03$, $p=.59)$. Therefore, we kept education as a separate variable but constructed an Economic Risk Index as the mean of the percentage below poverty and the percentage unemployed $(M=19.08, S D=7.26$, range: $1.35-39.85)$. To make sure that our measure of segregation was sensitive, rather than just taking either the percentage of African Americans or the percentage of Latinos as our measure, we followed the work of Massey and Denton (1988) who argued that segregation (and its opposite, diversity) are likely to be psychologically meaningful when one's own neighborhood differs from other neighborhoods in one's own town. Maly (2000) used this operationalization of segregation to create a Neighborhood Diversity Index (ND) and we used this measure. It is computed as the absolute value of the sum of differences between the percentage of each racial-ethnic group living in Detroit as a whole and the percentage of that group living in a particular census track. Because we make use of Massey and Denton (1988), we used Maly's formula as well. In our case, the formula is (IDetroit percentage white - Census Track percentage 
whitel + IDetroit percentage Black - Census Track percentage Blackl + IDetroit percentage Latino-Census Track percentage Latinol)/2. Higher ND scores represent more segregation and the ND can range from 0 to $1(M=0.40$, $S D=.28$, range: $0.02-0.85)$. Higher ND was correlated with more economic risk $(r=.23, p<.001)$ and less education $(r=-.59, p<.001){ }^{2}$

\section{Analyses Plan}

To study the effect of neighborhood segregation on racialethnic identity, we used multilevel modeling (MLM; Gelman and Hill 2006; Kreft and de Leeuw 1998; Raudenbush and Bryk 2002). The reason for using MLM rather than a multiple regression equation, is that MLM was developed to deal with nested data (multiple students living in the same census tract) which violates assumptions built into linear regression equations. MLM accommodates the hierarchical structure of the data and correctly models student level (Level 1) effects (race-ethnicity, gender), neighborhood level (Level 2) effects (segregation, poverty, education, and unemployment), and cross-level effects (interactions between student level and neighborhood level).

Data were analyzed using HLM 6.06. About $64 \%$ of our sample is nested in about $20 \%$ of the Census tracts, with each tract containing five or more children. Although there are relatively few youth in each of the remaining tracts, according to Snijders and Bosker (1999), HLM is the appropriate choice for analyses as the large number of tracts $(n=100)$ provides sufficient statistical power at level $2 .^{3}$

Although we looked for cross-level interactions, we did not find differences in the effect of the neighborhood variables by child race-ethnicity or gender. For parsimony, these analyses are available from the authors but not reported below. Similarly, education (percentage with less than high school education) was included in initial analyses but was not statistically significant, perhaps due to its high correlation with the segregation index $(r=0.59, p<.01)$. Results are substantively the same whether education is

\footnotetext{
$\overline{2}$ We use two as our denominator following Maly (2000), using three as the denominator does not change results.

3 There is a debate as to how many groups and how many observations per group are needed in MLM (Bickel 2007, p. 282; Maas and Hox 2005, p. 88; Kreft and de Leeuw 1998, p. 125; as compared to Gelman and Hill 2006, p. 275) but there is as yet no agreement. Using simulated data, Maas and Hox (2005) find that biased estimates of the second level standard errors occur only with small sample sizes of 50 or less. Since our level two sample size (census tract) is 100, our estimates should not be biased. Moreover, we also re-ran our analyses using ordinary least squares regression and found parallel effects, with comparable size of beta-weights for the ND index in both analyses.
}

included or not. Therefore, to simplify presentation, it is not included in the reported analyses, which included two neighborhood indices (economic risk and diversity).

\section{Results}

Prior to conducting the MLM, we first explored possible race-ethnicity and gender differences in racial-ethnic identity scores. We found an effect of race-ethnicity but not gender on racial-ethnic identity scores and an effect of gender but not race-ethnicity on GPA. Specifically, using multivariate analyses of variance (MANOVA), we found a significant overall effect of race-ethnicity (multivariate $F(3,316)=6.47, p<.001$ ) and not gender (multivariate $F$ $(3,316)=0.63, p=0.61)$ and no interaction between race-ethnicity and gender (multivariate $F(3,316)=0.29$, $p=0.83$ ) on racial-ethnic identity. Follow-up with analyses of variance (ANOVA), showed higher scores for African Americans on each of the three racial-ethnic identity components (connectedness $F(1,318)=3.95$, $p<.05$, awareness of racism $F(1,318)=18.80, p<.001$, and embedded achievement $F(1,318)=4.35, p<.05)$ compared to Latinos.

We then turned to the effect of neighborhood context on racial-ethnic identity scores. In the US, African Americans represent $12.4 \%$ of the population. However, in the city of Detroit, African Americans represent $82.8 \%$ of the population, with the remaining population of the city being mostly white of any ethnicity (10.4\%) or choosing "other races" (4\%) rather than other specific designation in the Census. Latinos (who can check white, Black or other race as well) represent $6.1 \%$ of the population. Thus, all the children in our sample lived in a city that is more African American than the country as a whole; our question, however, was whether this segregation was psychologically meaningful to them. Following Massey and Denton (1988) we examined the relative segregation of a child's own neighborhood compared to the city as a whole. Since the largest groups are African American and Latino, our basic question was whether living in neighborhoods with significantly higher than average concentrations of African Americans and/or Latinos influenced content of racialethnic identity. In our sample, Latino youth lived in more segregated neighborhoods than African American youth $(t(335)=-16.7655, p<.001)$.

As documented in Table 1 and presented graphically in Fig. 1, we found effects of segregation on youth racialethnic identity using MLM. Recall that initial descriptive MANOVA analyses showed higher racial-ethnic identity scores for African Americans on each of the three identity components, Connectedness, Awareness of Racism, and Embedded Achievement. However, as can be seen in 
Table 1 Effects of neighborhood economic risk and segregation on racial-ethnic identity (Connectedness, Embedded Achievement, and Awareness of Racism)

\begin{tabular}{|c|c|c|c|c|c|c|}
\hline \multirow[t]{2}{*}{ Parameter estimates } & \multicolumn{2}{|c|}{ Connectedness } & \multicolumn{2}{|c|}{ Embedded achievement } & \multicolumn{2}{|c|}{ Awareness of racism } \\
\hline & Estimate & $p$ & Estimate & $p$ & Estimate & $p$ \\
\hline \multicolumn{7}{|l|}{ For intercept $\left(\mathrm{B}_{0}\right)$} \\
\hline Constant $\left(\mathrm{G}_{00}\right)$ & 4.18 & 0.00 & 3.99 & 0.00 & 3.46 & 0.00 \\
\hline Risk context $\left(\mathrm{G}_{02}\right)$ & 0.00 & 0.66 & -0.01 & 0.23 & 0.00 & 0.64 \\
\hline Segregation (ND index) $\left(\mathrm{G}_{03}\right)$ & -0.30 & 0.09 & -0.43 & 0.01 & -0.61 & 0.05 \\
\hline Random error $\left(\mathrm{U}_{0}\right)^{\mathrm{a}}$ & 0.02 & $>0.50$ & 0.02 & $>0.50$ & 0.19 & 0.17 \\
\hline \multicolumn{7}{|l|}{ For race slope $\left(B_{1}\right)$} \\
\hline Constant $\left(\mathrm{G}_{10}\right)$ & 0.04 & 0.66 & 0.04 & 0.73 & 0.22 & 0.17 \\
\hline \multicolumn{7}{|l|}{ For gender slope $\left(B_{2}\right)$} \\
\hline Constant $\left(\mathrm{G}_{20}\right)$ & 0.06 & 0.46 & 0.01 & 0.94 & -0.12 & 0.25 \\
\hline
\end{tabular}

Note: ${ }^{a}$ Reported as standard deviation. Reported effects using hierarchical linear modeling are presented in full. Education was not included in the final model; it was not a significant predictor of any of racial-ethnic identity components, with zero-level coefficient and high $p$-values $(0.69$ for awareness of racism, 0.78 for embedded achievement, and 0.99 for connectedness). In this table, effects of child race and child gender are not significant, neither are the effects of neighborhood risk, only the effect of neighborhood segregation is significant. Each of the variables is used to predict racial-ethnic identity in the following equations. First, at level 1 (individual child) racial-ethnic identity $=\mathrm{B}_{0}+$ $\mathrm{B}_{1} *$ Race $+\mathrm{B}_{2} *$ Gender + Disturbance, where $\mathrm{B}_{0}$ is intercept, $\mathrm{B}_{1}$ is the slope of race, and $\mathrm{B}_{2}$ is the slope of gender. Then, at Level 2 (neighborhood level)

Racial ethnic identity $=$ Constant $\left(\mathrm{G}_{00}\right)+\mathrm{G}_{02} *$ Risk context $+\mathrm{G}_{03} *$ Segregation $(\mathrm{ND}$ index $)+$ Random error $\left(\mathrm{U}_{0}\right)$

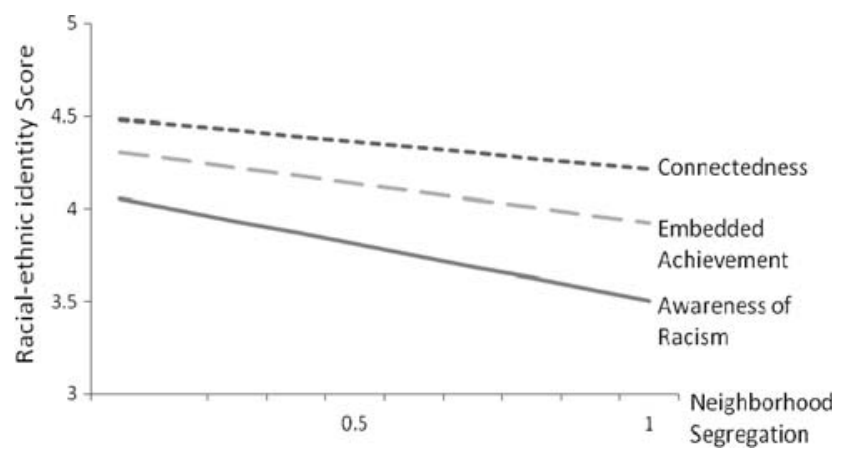

Fig. 1 Effect of neighborhood segregation on racial-ethnic identity (Connectedness, Awareness of Racism, and Embedded Achievement) score

Table 1, race-ethnicity was not a significant predictor of the racial-ethnic identity scores in the MLM analyses which took into account the neighborhood context. Indeed, neither neighborhood economic risk nor race-ethnicity or gender had significant effects after the segregation index (ND) was in the model. Specifically, as can be seen in Fig. 1, higher neighborhood segregation is associated with lower scores on all three of the racial-ethnic identity components (Connectedness, Embedded Achievement, and Awareness of Racism). Segregation undermines racial-ethnic identity. Effects are significant for Embedded Achievement (parameter estimate $=-0.43, p<.01$ ) and Awareness of Racism (parameter estimate $=-0.61, p<0.05$ ), and at trend level for Connectedness (parameter estimate $=$ $-0.30, p<0.09$ ). Thus, living in neighborhoods that were more segregated than the rest of Detroit predicted lower racial-ethnic identity scores among Latino and African American eighth graders. Segregation seems to undermine youths' ability to believe that achievement is part of in-group identity, to notice structural barriers to success and even to feel connected to their racial-ethnic in-group. We did not find interactions between neighborhood factors and either race-ethnicity or gender, though it is possible that effects would have been found if our sample included more census tracts.

\section{Discussion}

Seventy years ago, Clark and Clark (1939) argued that segregation was bad for the academic outcomes of minority youth because it had pernicious consequences for their identities. While their own doll studies were not necessarily as clearly interpretable as they would have hoped, the idea that segregation matters has found renewed interest among social scientists, in part because of a resegregation of low income American inner city neighborhoods (Massey and Denton 1989, 1993; Wacquant and Wilson 1989). How might living in a context that is both segregated and lacking in employment and income impact youths? A number of modern studies have demonstrated negative effects of racial segregation on academic outcomes net of other effects American youth (Hanushek et al. 2002). But these studies do not explain how segregation is psychologically depleting. In the current article, we proposed that 
segregation depletes youth of an important psychological resource for academic success, which is a mindset that academic success is valued by their racial-ethnic in-group and that doing well in school is a valued goal for members of one's racial-ethnic group even though one's group may not be doing well due to stereotypes and other barriers. That is, segregation is psychologically depleting by stripping racial-ethnic identity of its ability to perform an important self-improvement function.

Indeed, our results demonstrate that racial-ethnic segregation undermines racial-ethnic identity in this sample. We find effects in an inner city sample of neighborhoods differing in both racial-ethnic diversity and poverty and unemployment. We do not find additional negative effects of poverty and unemployment after segregation is taken into account.

We interpret these results to mean that growing up in a neighborhood with high poverty and unemployment rates does not itself undermine racial-ethnic identity. Rather it is the added negative effect of being in a racially-ethnically concentrated neighborhood in which people belonging to an important social identity group are likely to have few resources (live in poverty and not have employment) that is sapping of positive racial-ethnic identity. What is important in our results is that this negative effect occurs for those racial-ethnic identity factors that contribute to positive academic outcomes-embedded achievement, connectedness, and awareness of racism. Our results suggest that growing up in a segregated inner city urban neighborhood makes it harder to believe that academic success is valued and normative in one's racial-ethnic group. Results also suggest that effects are due to segregation, not to poverty, or to unemployment alone. It may be that segregation makes it harder to notice negative stereotypes about one's group and other barriers to success.

In the current study, eighth grade African American and Latino students were less likely to highly endorse key components of racial-ethnic identity-embedded achievement and awareness of racism (and at trend level, connectedness) when they lived in neighborhoods that were more segregated than the city in which they lived as a whole. These negative effects of segregation were not moderated by gender or race-ethnicity. These results are important because prior research found that African American and Latino students with higher racial-ethnic identity scores on embedded achievement, connectedness, and awareness of racism scores did better academically (independently of their connectedness score) (e.g., Oyserman 2003a, b). Studies using these tripartite scales showed effects of racial-ethnic identity on concern about school controlling for prior grades (Oyserman et al. 2003a, b) as well as persistence in school tasks (Oyserman et al. 1995). These studies also showed that controlling for prior school engagement and attainment, eighth graders with higher racial-ethnic identity fared better both over the course of the academic year and in their transition to high school. Specifically, they were less likely to experience decline in academic efficacy (Oyserman et al. 2001) and school involvement (Oyserman et al. 2003a, b), and are likely to attain better grades in school (Altschul et al. 2006). Taken together with prior research, the current results imply that even in low income neighborhoods, racial-ethnic identity can have positive effects on youth academic outcomes but that living in highly segregated neighborhoods makes sustaining high racial-ethnic identity more difficult.

A limitation of our study that is shared by other work on the effects of segregation on racial-ethnic identity and academic outcomes is that we focus on a single city. Demonstrating effects across cities would allow for a more robust analyses of the size of effects. While the strength of our study is our ability to demonstrate effects on racialethnic identity constructs previously associated with school performance, there are a number of limitations to our current approach. Sample size did not allow for testing the effects of racial-ethnic identity on grades simultaneously with testing the effects of neighborhoods on racial-ethnic identity. African American and Latino youth lived in differentially segregated neighborhoods and differed in mean racial-ethnic identity scores. These differences may be due to differences in neighborhood segregation, only a larger sample with a range of neighborhood segregation for both Latino and African American youth would allow us to fully test for this possibility. We also did not have longitudinal data on racial-ethnic identity. Other studies with longitudinal data suggest that embedded achievement, awareness of racism, and connectedness are relatively stable in the transition from eighth to ninth grade (Altschul et al. 2006) with an upward trend toward higher racial-ethnic identity scores with the transition to high school, a pattern that did not vary by race-ethnicity. Altschul et al. interpreted this trend upward in racial-ethnic identity as being due to the greater heterogeneity of high schools, which take in students from larger areas of the city than do middle schools. Thus, they also proposed that diversity is helpful for racialethnic identity. However, this prior study did not analyze the effect of neighborhood context (Altschul et al. 2006), and it is possible that the effect of entering a more diverse high school moderates the depleting effect of home neighborhood segregation. Time series data would allow for analyses of the competing effects of greater school heterogeneity versus neighborhood racial-ethnic segregation. Our current data imply competing effects which could be examined directly only in a larger sample including more schools with greater heterogeneity.

That said, our study also has a number of important strengths. We obtained data from a number of sources 
(youth report of identity and census data), reducing the possibility that effects are due to being from a single source. We used a measure of racial-ethnic identity previously shown to predict school performance. We used a sensitive measure of racial segregation, developed by Maly (2000), that operationalizes Massey and Denton's (1988) description of residential segregation. Thus, our analyses focus on the relative segregation of one's own neighborhood compared to the city as a whole and demonstrate that relative segregation matters. Results do not depend on the participant's explicit attitudes about segregation since they were aggregated from census data and not from self-report. Results show negative effects on racial-ethnic identity and are congruent with other research demonstrating negative effects of segregation (increasing for example homicide among strangers and acquaintances, Peterson and Krivo 1993). Peterson and Krivo (1993) interpret their results as demonstrating negative effects of social isolation on social cohesion. Their interpretation consistent with the argument that Sampson (2003) makes, which is that segregation reduces collective efficacy, creating a sense that people in one's own neighborhood cannot work together to supervise children or solve problems. Congruent with this interpretation, our data suggest that segregation is also undermining of social identities, dampening expression of those components of racial-ethnic identity that have been shown to strengthen African American and Latino youths academic involvement and attainment. We show negative effects of living in higher segregated neighborhoods in an urban area that is not majority white. This finding suggests that negative effects of segregation are not limited to contexts in which majorities are white, which is important because urban centers are often majority minority and include neighborhoods varying in segregation. Our results suggest that this variability matters.

Our results are also congruent with research attempting to understand how and when contexts carry with them negative stereotyping about social identities such as raceethnicity (Bigler and Liben 2007). Bigler and Liben (2007) provide evidence that when a social identity is used to make meaning, it becomes psychologically salient. Our analyses suggest that in segregated contexts, one's own race-ethnicity can be psychologically meaningful in ways that are undermining of those components of racial-ethnic identity that matter for school success. While poverty and unemployment alone do not undermine racial-ethnic identity, segregation does.

Acknowledgments We would like to thank all the students who participated in this study as well as the interviewers, Jillian Fortain who obtained the Census Track Data and Deborah Bybee who helped with preliminary analyses. Funding for data collection came from the National Institutes of Health (NIMH R01 MH58299).

\section{References}

Adelman, R. M., \& Gocker, J. C. (2007). Racial residential segregation in urban America. Sociology Compass, 1, 404-423.

Altschul, I., Oyserman, D., \& Bybee, D. (2006). Racial-ethnic identity in mid-adolescence: Content and change as predictors of grades. Child Development, 77, 1155-1169.

Arroyo, C., \& Zigler, E. (1995). Racial identity, academic achievement, and the psychological well-being of economically disadvantaged adolescents. Journal of Personality and Social Psychology, 69, 903-914.

Bankston, C., \& Caldas, S. J. (1996). Majority African American schools and social injustice: The influence of de facto segregation on academic achievement. Social Forces, 75(2), 535-555.

Bennett, D. M. (2006). Cultural resources and school engagement among African American youths: The role of racial socialization and ethnic identity. Children \& Schools, 28, 197-206.

Bickel, R. (2007). Multilevel analysis for applied research: It's just regression! New York: The Guilford Press.

Bigler, R., \& Liben, S. (2007). Developmental intergroup theory: Explaining and reducing children's social stereotyping and prejudice. Current Directions in Psychological Science, 16, 162-166.

Chavous, T. M., Bernat, D. H., Schmeelk-Cone, K., Caldwell, C. H., Kohn-Wood, L., \& Zimmerman, M. A. (2003). Racial identity and academic attainment among African American adolescents. Child Development, 74, 1076-1090.

Chavous, T., Rivas, D., Green, L., \& Helaire, L. (2002). Role of student background, perceptions of ethnic fit, and racial identification in the academic adjustment of African American students at a predominantly white university. Journal of Black Psychology, 28, 234-260.

Clark, K. (1965/1989). Dark Ghetto: Dilemmas of Social Power. Wesleyan Edition, Wesleyan University Press.

Clark, K., \& Clark, M. (1939). The development of consciousness of self and the emergence of racial identification in Negro preschool children. Journal of Social Psychology, 10, 591-599.

Eggers, M., \& Massey, D. (1992). A longitudinal analysis of urban poverty: Blacks in U.S. metropolitan areas between 1970 and 1980. Social Science Research, 21, 175-203.

Gelman, A., \& Hill, J. (2006). Data analysis using regression and multilevel/hierarchical models. New York: Cambridge University Press.

Hanushek, E. A., Kain, J. F., Rivkin, S. G. (2002). New evidence about Brown v. Board of Education: The complex effects of school racial composition on achievement. NBER Working paper no. 8741 .

House, J. S. (2002). Understanding social factors and inequalities in health: 20th century progress and 21 st century prospects. Journal of Health and Social Behavior, 43, 125-142.

Howard, J. (2000). Social psychology of identities. Annual Review of Sociology, 26, 367-393.

Hraba, J., \& Grant, G. (1970). Black is beautiful: A reexamination of racial preference and identification. Journal of Personality and Social Psychology, 16, 398-402.

Kibour, Y. (2001). Ethiopian immigrants' racial identity attitudes and depression symptomatology: An exploratory study. Cultural Diversity \& Ethnic Minority Psychology, 7, 47-58.

Kreft, I. G. G., \& de Leeuw, J. (1998). Introducing multilevel modeling. Thousand Oaks, CA: Sage Publications.

Krivo, L. J., Peterson, R. D., Rizzo, H., \& Reynolds, J. R. (1998). Race, segregation and the concentration of disadvantage: 19801990. Social Problems, 45(1), 61-80.

Luhtanen, R., \& Crocker, J. (1992). A collective self-esteem scale: Self-evaluation of one's social identity. Personality and Social Psychology Bulletin, 18, 302-318. 
Maas, C. J. M., \& Hox, J. J. (2005). Sufficient sample sizes for multilevel modeling. Methodology, 1, 86-92.

Maly, M. (2000). The Neighborhood Diversity Index: A complementary measure of racial residential settlement. Journal of Urban Affairs, 22, 37-47.

Martinez, R., \& Dukes, R. (1997). The effects of ethnic identity, ethnicity, and gender on adolescent well-being. Journal of Youth and Adolescence, 26, 503-517.

Massey, D. S., \& Denton, N. (1988). The dimensions of residential segregation. Social Forces, 67, 281-315.

Massey, D. S., \& Denton, N. (1989). Hypersegregation in US Metropolitan areas: Black and Hispanic segregation along five dimensions. Demography, 26, 373-391.

Massey, D. S., \& Denton, N. (1993). American apartheid: segregation and the making of the underclass. Cambridge, MA: Harvard University Press.

Massey, D. S., \& Eggers, M. L. (1990). The ecology of inequality: Minorities and the concentration of poverty, 1970-1980. The American Journal of Sociology, 95(5), 1153-1188.

Massey, D. S., Gross, A., \& Shibuya, K. (1994). Migration, segregation, and the geographic concentration of poverty. American Sociological Review, 59, 425-445.

O'Brien, V., Martinez-Pons, M., \& Kopala, M. (1999). Mathematics self-efficacy, ethnic identity, gender, and career interests related to mathematics and science. Journal of Educational Research, $92,231-235$.

Oyserman, D. (2008). Racial-ethnic self-schemas: Multi-dimensional identity-based motivation. Journal of Research on Personality, 42, 1186-1198.

Oyserman, D., Brickman, D., \& Rhodes, M. (2007). Racial-ethnic identity in adolescence: Content and consequences for African American and Latino and Latina youth. In A. Fuligni (Ed.), Contesting stereotypes and creating identities: Social categories, identities and educational participation (pp. 91-114). New York: Russell-Sage.

Oyserman, D., Bybee, D., \& Terry, K. (2003a). Gendered racial identity and involvement with school. Self and Identity, 2, 1-18.

Oyserman, D., Bybee, D., \& Terry, K. (2006). Possible selves and academic outcomes: How and when possible selves impel action. Journal of Personality and Social Psychology, 91, 188-204.

Oyserman, D., Gant, L., \& Ager, J. (1995). A socially contextualized model of African American identity: Possible selves and school persistence. Journal of Personality and Social Psychology, 69, $1216-1232$.

Oyserman, D., Harrison, K., \& Bybee, D. (2001). Can racial identity be promotive of academic efficacy? International Journal of Behavioral Development, 25, 379-385.

Oyserman, D., Kemmelmeier, M., Fryberg, S., Brosh, H., \& HartJohnson, T. (2003b). Racial-ethnic self-schemas. Social Psychology Quarterly, 66, 333-347.

Oyserman, D., \& Markus, H. (1993). The sociocultural self. In J. Suls \& A. G. Greenwald (Eds.), Psychological perspectives on the self, Vol. 4 (pp. 187-220). Hillsdale, NJ: Lawrence Erlbaum Associates.

Parham, T., \& Helms, J. (1985). Attitudes of racial identity and selfesteem of Black students: An exploratory investigation. Journal of College Student Personnel, 26, 143-147.

Peterson, R. D., \& Krivo, L. J. (1993). Racial segregation and black urban homicide. Social Forces, 71(4), 1001-1026.

Phillips, T. M., \& Pittman, J. F. (2003). Identity processes in poor adolescents: Exploring the linkages between economic disadvantage and the primary task of adolescence. Identity: An International Journal of Theory and Research, 3, 115-129.

Pierre, M. R., \& Mahalik, J. R. (2005). Examining African selfconsciousness and black racial identity as predictors of Black men's psychological well-being. Cultural Diversity \& Ethnic Minority Psychology, 11, 28-40.

Pillay, Y. (2005). Racial identity as a predictor of the psychological health of African American students at a predominantly white university. Journal of Black Psychology, 31, 46-66.

Pyant, C., \& Yanico, B. (1991). Relationship of racial identity and gender-role attitudes to Black women's psychological wellbeing. Journal of Counseling Psychology, 38, 315-322.

Raudenbush, S. W., \& Bryk, A. S. (2002). Hierarchical linear model: Applications and data analysis methods. Thousand Oaks, CA: Sage.

Rowley, S. J., Sellers, R. M., Chavous, T. M., \& Smith, M. A. (1998). The relationship between racial identity and self-esteem in African American college and high school students. Journal of Personality and Social Psychology, 74, 715-724.

Sampson, R. (2003). The neighborhood context of well-being. Perspectives in Biology and Medicine, 46(Suppl), S53-S64.

Sellers, R., Smith, M., \& Shelton, J. (1998). Multidimensional model of racial identity: A reconceptualization of African American racial identity. Personality and Social Psychology Review, 2, 18-39.

Snijders, T. A. B., \& Bosker, R. (1999). Multilevel analysis: An introduction to basic and advanced multilevel modeling. Thousand Oaks, CA: Sage Publications.

Steele, C. (1997). A threat in the air: How stereotypes shape intellectual identity and performance. American Psychologist, $52,613-629$.

Steele, C., Spencer, S., \& Aronson, J. (2002). Contending with group image: The psychology of stereotype and social identity threat. Advances in Experimental Social Psychology, 34, 379-440.

Stevenson, H. (1995). Relationship of adolescent perceptions of racial socialization to racial identity. Journal of Black Psychology, 21, 49-70.

Stevenson, H. (2005, October). Playing with anger: A cultural socialization intervention to help Black youth manage hypervulnerability. Sundberg Conference, University of Oregon, Eugene Oregon.

Swanson, D., Spencer, M. B., \& Harpalani, V. (2003). Psychosocial development in racially and ethnically diverse youth: Conceptual and methodological challenges in the 21 st century. Development and Psychopathology, 15, 743-771.

Tajfel, H., \& Turner, J. (1986). The social identity theory of intergroup behavior. In W. Austin \& S. Worchel (Eds.), Psychology of intergroup relations (2nd ed., pp. 7-24). Chicago: Nelson-Hall.

Taylor, S., Repetti, R., \& Seeman, T. (1997). Health psychology: What is an unhealthy environment and how does it get under the skin? Annual Review of Psychology, 48, 411-447.

Vandiver, B. J., Cross, W. E. J., Worrell, F. C., \& Fhagen-Smith, P. E. (2002). Validating the cross racial identity scale. Journal of Counseling Psychology, 49, 71-85.

Wacquant, L. J., \& Wilson, J. W. (1989). The cost of racial and social class segregation in the inner city. Annuals of the American Academy of Political and Social Science, 501, 8-25.

Wallace, J., \& Muroff, J. (2002). Preventing substance abuse among African American children and youth: Race differences in risk factor exposure and vulnerability. The Journal of Primary Prevention, 22, 235-261.

Wilson, W. J. (1996). When work disappears: The world of the new urban poor. New York, NY: Alfred A. Knopf Inc.

Worrell, F. C., Vandiver, B. J., Cross, W. E. J., \& Fhagen-Smith, P. E. (2004). Reliability and structural validity of cross racial identity scale scores in a sample of African American adults. Journal of Black Psychology, 30, 489-505. 